\title{
Publisher Correction: Tackling food consumption inequality to fight hunger without pressuring the environment
}

Tomoko Hasegawa (D), Petr Havlík, Stefan Frank (D), Amanda Palazzo (D) and Hugo Valin (D)

Correction to: Nature Sustainability https://doi.org/10.1038/s41893-019-0371-6, published online 11 September 2019.

In the version of this Article originally published, the positioning of the tick-mark labels in Fig. 3 was incorrect, and should have been as shown below. This has now been corrected in the Article.

Published online: 11 November 2019

https://doi.org/10.1038/s41893-019-0439-3

(c) The Author(s), under exclusive licence to Springer Nature Limited 2019 


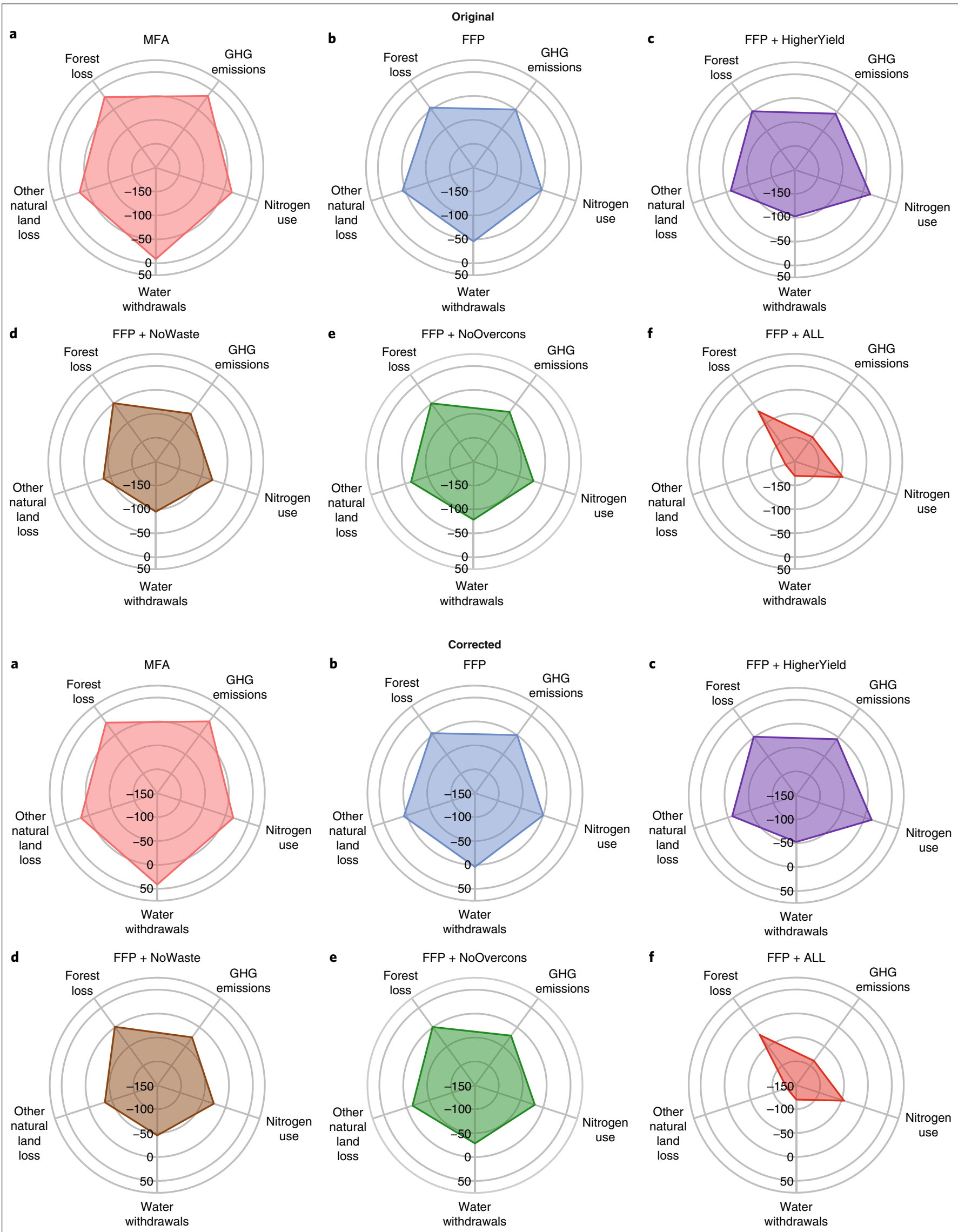

Fig. 3 | Original and corrected. 